\title{
Hormones and Fitness Elements: Impact of Football Training on College Student Players
}

\author{
Syed Ibrahim ${ }^{1 *}$, Syed Azhar Ahmed ${ }^{2}$, Syed Muneer Ahmed ${ }^{3}$, Syed Kaleem Ahmed ${ }^{4}$ \\ ${ }_{1}^{1}$ Physical Education Department, King Fahd University of Petroleum \& Minerals, Dhahran, 31261, \\ Saudi Arabia. \\ ${ }^{2}$ Freelance Physiotherapist, Hyderabad, Telangana, India- 500004. \\ ${ }^{3}$ Tennis Coach, GHMC, Hyderabad, Telangana, India- 500004. \\ ${ }^{4}$ Freelance Tennis Coach, Hyderabad, Telangana, India, 500004.
}

\begin{abstract}
The aim was to find the effectiveness of football training on hormones and fitness components of college male student players. 26 underweight footballers aged 18 to 19 with Body Mass Index $<18.5 \mathrm{~kg} / \mathrm{m}^{2}$ and fat free mass (FFM) were divided into two groups: Training Group-1 (FFM (40-45 kg), $\mathrm{n}=12$ ) and Training Group-2 (FFM (46-55 kg), $\mathrm{n}=14$ ). They were tested on body features, triiodothyronine (T3), thyroxine (T4), thyroid-stimulating hormone (TSH), speediness $(20 \mathrm{~m}, 40 \mathrm{~m}, 60 \mathrm{~m})$, standing long jump (SLJ), sit-ups, agility, and seat and reach parameters at pre- and post-training programs. Both groups completed plyometric regime succeeded by sprinting small distances and football contests for 6 weeks, twice a week, and 40 $\mathrm{m}$ every period. Data were analyzed using the independent and paired t-test with a significance level of $\mathrm{P} \leq$ 0.05. The outcomes exhibited that TG-1 and TG-2 improved in BM, BMI, FFM, SLJ, sit-ups, and sit \& reach by $4.6,4.4,4.6,3.8,29.4$, and $12 \%$, and by $4.6,5.5,3.4,3.7,21$, and $13 \%$, respectively (P $\leq 0.05)$. TG-1 and TG-2 decreased by $7.2,3.6,3.5$, and $23.1 \%$ and by $6.5,4.8,4.0,4.1$, and $11.4 \%$, in $20 \mathrm{~m}$, 40m, agility, and FT3, respectively. It was established that 6 weeks of football training affects power, muscular endurance, flexibility, speed, and FT3 of 2 groups of underweight college male students apart from having similar outcomes with regard to the FFM.
\end{abstract}

Keywords: Underweight Males, Hormones, Training, Power, Speed, Muscular Endurance, Flexibility, Illinois Agility

HOW TO CITE THIS ARTICLE: Syed Ibrahim, Syed Azhar Ahmed, Syed Muneer Ahmed, Syed Kaleem Ahmed: Hormones and Fitness Elements: Impact of Football Training on College Student Players, Entomol Appl Sci Lett, 2020, 7(4): 102-111.

Corresponding author: Syed Ibrahim

E-mail $\bowtie$ sibrahim @ kfupm.edu.sa

Received: $21 / 08 / 2020$

Accepted: $16 / 12 / 2020$

\section{INTRODUCTION}

Soccer is the most glamorous sport containing different skills and activities such as jumping, tackling, and sprinting $[1,2]$. It is an exceedingly attractive, prominent, and crowed pleasing game in the globe and the most acceptable enjoyable and popular sport by elite and traditional people such as teenagers, staff, students, men, ladies, and leans [2]. In a soccer match, sprinting of $10-15 \mathrm{~m}$ (2-4 seconds) occurs every 1.5 minutes [3]. $3 \%$ of the playing period and 1 $11 \%$ of the distance covered are taken by sprinting in a match [4]. It was established that much of the sprint stints are smaller than $30 \mathrm{~m}$ and about partial of the sprints are fewer than $10 \mathrm{~m}$ in distance [4].

Plyometric is a quick and potent effort that stimulates the development of performance in sport via the functional alteration that takes place in the central nervous system. Several research works have focused on the influence of mixed resistance and plyometric exercise on speed [5-7], power [8], agility [9], and flexibility $[9,10]$ of men subjects. A study has explored the effect of mixed plyometric-sprint and weight exercise regimes with the Meridian elite sporty shoe for speed and power in females [11]. Further investigation has detected the impact of 6weeks of unified sprint and jumps exercise on speed for teenage male footballers [12]. The 
outcomes of some of these investigation studies exhibited that there is a noteworthy dissimilarity amongst groups at a sprint time [13], power [13], strength [14], agility, and flexibility [9]. Many of the research work established that these components had presented comparable consequences between groups [5-8]. Conversely, a few studies have confirmed the assertive training impacts when the pre-test was matched with the post-test [6, 7, 9]

Sprinting is a powerful tool in sporting activities that consists of three stages; acceleration, maximum, and deceleration [15-17]. There was no exercise impact among groups after $20 \mathrm{~m}$ of sprint training among male subjects [18]. Investigations have revealed a noteworthy change in the $20 \mathrm{~m}$ sprint by $3.1 \%$ [16] and a significant decline in $40 \mathrm{~m}$ sprint by $1.1 \%$ [7] and $5.6 \%$ [11]. In a $60 \mathrm{~m}$ sprint, a substantial reduction by $8 \%$ was reported by previous research [11]. The agility times dropped profoundly by $1.5 \%$ [19], 4.3\% [16], 1.7\% [20], and $3 \%$ [21] after working out. In contrast, no alterations were observed in agility times [22, 23]. In the SLJ, an earlier study pointed out remarkable modifications between groups [24], but another study reported similar results [9]. Many previous studies stated remarkable rises in SLJ by $10 \%$ [10], 2.8 to $3.2 \%$ [16], 10 to $14 \%$ [8], 5.5\% [24], and 7 to 9\% [11]. At sit and reach, there was no disparity 6weeks after plyometric training among male swimmer athletes aged 11-14 years. [10]. The sit-ups went up remarkably by had surges of $66.6 \%$ after two months of circuit power endurance drill amongst underweight men college students [25].

An underweight subject is a person whose BMI is less than $18.5 \mathrm{~kg} / \mathrm{m}^{2}[26,27]$. It is considered a health problem, related to some medical risk elements such as hyperthyroidism, food deficiency, sickness, and genetic. It can be treated using sprint and weight training which develops weight advantage [11], muscle tone, and bone mineral density [18]. Plyometric training makes muscle hypertrophy and leads to weight increase for lean subjects. Increasing calorie consumption also can take place for the treatment of lean people. Investigators overlooked the lean persons, and this can be observed noticeably in the literature.
Triiodothyronine (T3) and thyroxine (T4) are the basic thyroid gland hormones, which control the growth and speed of the work of several organisms in the human body. They increase body metabolism and cause the cardiac system to be highly sensitive to sympathetic nervous system. TSH is a hypothalamus hormone and its excretion is stimulated when $\mathrm{T} 4$ production is low. TSH production is inhibited when T4 is high. The main influence of TSH is to stimulate T4 excretion. A noteworthy decline in FT3 was observed by one of the previous investigators after training [28, 29]. A significant boost in FT3 was stated after a week of intense weight training by youth woman weightlifters [30]. Nonetheless, no changes were observed in the FT3 after weight training [31, 32]. No modifications in FT4 were noted [31, 32]. A noteworthy reduction in FT4 was testified [33]. Extraordinary decreases were identified in TSH after weightlifting exercise [30,33]. Nevertheless, no alteration in TSH was shown [31, 32].

In our view, there was scarcely any exploration that scrutinized the effectiveness of football exercise drills on FT3, FT4, TSH of underweight college men students whose BMI was <18.5 $\mathrm{kg} / \mathrm{m}^{2}$ and the FFM fluctuated between 40-45 and 46-55 kg. Hence, the primary purpose of this search was to evaluate the impact of football intervention on certain hormones, speed, power, muscular endurance, agility, and flexibility of underweight university subjects.

\section{METHOD}

\section{Subjects}

Twenty-six underweight students from King Fahd University of Petroleum and Minerals (KFUPM) joined as subjects. The participants were selected based on two aspects, 1) the body mass index (BMI) was lower than $18.5 \mathrm{~kg} / \mathrm{m}^{2} .2$ ) the fat-free mass (FFM) fluctuated amid 40 to 45 and 46 to $55 \mathrm{~kg}$. The subjects were divided into two training group-1 (TG-1, FFM (40-45 kg), n = 12) and training group-2 (TG-2, FFM (46-55 kg), $n=14$ ). The agreement of the participants was determined for their optional involvement throughout the study period. The participants were asked to eliminate their agreement in case they felt any discomfort during the period of participation in the study. 


\section{Procedures}

The dependent components that were scrutinized in this research investigation were physical features (age, H, BM, BMI, \%BF, FFM), hormones (FT3, FT4, TSH), sprint (20m, 40m, $60 \mathrm{~m}$ ), alteration of course (Illinois Agility test), power (SLJ), muscular endurance (sit-ups for 30 seconds), and flexibility (sit \& reach). The modification stage began one week before pretesting. The time was recorded by a digital stopwatch (Casio HS70W, China) via a timer. A rest period of 5 min was allowed between trials. Each student was permitted with two rounds and the best one was registered. The participants were directed to warm up before the tests and each exercise session for 5 minutes and to cool down after tests and each training unit for 5 minutes.

\section{Physical characteristics (PC)}

Both groups were tested pre- and post-study for PC. Before the start of the working out, their weight was measured by SECA (medical balance - Germany) to approximate 100 grams. The height was assessed to about one centimeter. The BMI was computed by dividing the BM in kilograms over the height in meter squared. \%BF was assessed via Harpenden (skinfold caliper) at 4 sites; biceps, triceps, sub-scapular, and abdomen [34]. The FFM was assessed by multiplying the $\mathrm{BM}$ by the $\% \mathrm{BF}$, then subtracting the current result from the BM.

\section{Hormones}

The hormones measured in this study were T3, $\mathrm{T} 4$, and TSH. The plasma samples were collected at pre-tests and post-tests. The plasma was drowned from the veins and collected in tubes and instantaneously frozen for future calculation. The biochemical measurements took place in the KFUPM laboratory.

\section{0m, 40m, 60m Sprint}

In the $20 \mathrm{~m}, 40 \mathrm{~m}$ and $60 \mathrm{~m}$ sprint, the subjects were administered to run with maximum speed from the beginning to the end in their lanes. A single student was involved in each running trail for precise timing. The trail was executed on a track and the participants were requested to the position immediately behind the start mark in each sprint runs independently. On the signal of the starter, the subject was asked to start the run and the time was documented to the nearby 100 of a second.

\section{Standing Long Jump (Explosive Power)}

In SLJ, the student was requested to a position rear of the board for take-off, keeping the feet at a distance and the knees bent. He was directed to jump the farthest with the swing of the arms. The jumped distance was assessed by a meter from the start mark to the portion of the body that touched the ground bordering the jumping board. The scorer was directed to stand at the side to observe the landing mark.

\section{Sit-ups (Muscular Endurance)}

The subject was administered to lie down in a supine position on a rug with knees bent less than 90 degrees and touch each other, feet put together, and heel 30 centimeters apart from buttocks. Hands crossed and kept on the chest, and the head was on the mat. The feet were held by the partner to keep them in touch with the floor. On the signal "go", the participant was requested to lift his body from the floor with his head up, which was counted as one sit up. Return to the initial position with the back on the floor before the next set up was compulsory. Sit up concluded on the command stop. The number of the correct execute sit-ups performed in 30 seconds duration were scored.

\section{Sit \& Reach (Flexibility)}

The participants were asked to remove the shoes and sit on the ground facing the flexibility punnet with knees fully stretched and feet kept flat in contrast to the box and about four inches apart. The subjects were directed to reach as far as possible with palms down and one hand placed over the other. They were directed to hold this position for a maximum of 1 to 2 seconds, keeping the knees locked at all the time.

\section{Illinois Agility Test}

This test was established by 4 cones designing the agility external border; 10 meters long and 5 meters wide. The cone at point $\mathrm{A}$ designs the beginning line. The Cones at $\mathrm{B}$ and $\mathrm{C}$ to spot the turning points. The cone at point $\mathrm{D}$ to spot the end line. 4 additional cones were located in the center of the test region 3.3 meters away from each other. The subject started stretching on the floor, face down with hands slightly behind the shoulder levels (cone A). The subject sprinted as 
quick as he could after the command "go" and when crossing the start line, the time was started. The subject had to turn to the right at cone $\mathrm{B}$ towards the cone in the center (between $\mathrm{A}$ and D cones) turning to the left and right (4 cones). When the subject reached the cone in the center for the second time, he had to turn to the left towards the $\mathrm{C}$ cone, then turning to the right towards the D cone; the finishing line. As soon as the subject moved across the end line, the time was recorded by the starter. In the turns of cones $\mathrm{B}$ and $\mathrm{C}$, the subject had to touch the cones by hand to finish the assessment.

\section{Training Program (TP)}

The TP continued for one and a half months, 2 times per week, and 40 minutes every meeting. The two TGs executed plyometric workouts and sprints for 20 minutes preceded a football match of 20 minutes duration. In every phase of the exercise session, the participants were asked to perform 3 sets per workout. Every set included long jump, single-leg hop, and double leg hop preceded by sprinting for 20, 30, and $40 \mathrm{~m}$, respectively. All subjects were requested to execute the plyometric exercise regime with complete altitude and distance and to run with full speed.

\section{Data Analysis}

Mean and standard deviation were computed for all values via SPSS version 16.0 software. The Paired t-test was employed to recognize any significant difference within the group independently. The independent t-test was used to distinguish amongst groups (Post-tests minus pre-tests). The significance level was fixed at $\mathrm{P} \leq$ 0.05 .

\section{RESULTS}

Table 1: Physical characteristics variables calculated at pre and post training.

\begin{tabular}{|c|c|c|c|c|}
\hline \multirow{3}{*}{ Parameters } & Tests & $\begin{array}{c}\text { TG-1 } \\
\text { FFM } \begin{array}{c}40-45 \mathrm{~kg} \\
\mathrm{n}=12\end{array}\end{array}$ & $\begin{array}{c}\text { TG-2 } \\
\text { FFM }=46-55 \mathrm{~kg} \\
\mathrm{n}=14\end{array}$ & P-Values \\
\hline Age (y) & Pre & $18.58 \pm 0.51$ & $18.43 \pm 0.51$ & 0.452 \\
\hline Height (cm) & Pre & $168.50 \pm 5.50$ & $174.36 \pm 4.76$ & $0.007^{*}$ \\
\hline \multirow{3}{*}{$\begin{array}{c}\text { Body Mass } \\
(\mathrm{kg})\end{array}$} & Pre & $46.91 \pm 2.70$ & $53.76 \pm 3.39$ & $0.000^{*}$ \\
\cline { 2 - 5 } & Post & $49.08 \pm 2.76$ & $56.25 \pm 3.78$ & $0.000^{*}$ \\
\cline { 2 - 5 } Body Mass Index & Change & $2.16 \pm 1.37$ & $2.48 \pm 2.41$ & 0.689 \\
\hline \multirow{3}{*}{$\left(\mathrm{kg} / \mathrm{m}^{2}\right)$} & Pre & $16.48 \pm 1.17$ & $17.57 \pm 0.80$ & $0.010^{*}$ \\
\cline { 2 - 5 } & Post & $17.21 \pm 1.20$ & $18.54 \pm 1.15$ & $0.009^{*}$ \\
\cline { 2 - 5 } & Change & $0.73 \pm 0.53$ & $0.96 \pm 1.09$ & 0.513 \\
\hline \multirow{3}{*}{$(\%)$} & Pre & $9.75 \pm 3.25$ & $9.37 \pm 1.81$ & 0.717 \\
\cline { 2 - 5 }$(\%)$ & Post & $9.62 \pm 3.46$ & $10.12 \pm 2.65$ & 0.678 \\
\cline { 2 - 5 } & Change & $-0.12 \pm 1.24$ & $0.75 \pm 1.50$ & 0.124 \\
\hline \multirow{2}{*}{$\begin{array}{c}\text { FFM } \\
(\mathrm{kg})\end{array}$} & Pre & $42.30 \pm 1.83$ & $48.75 \pm 2.82$ & $0.000^{*}$ \\
\cline { 2 - 5 } & Post & $44.28 \pm 1.67$ & $50.44 \pm 2.88$ & $0.000^{*}$ \\
\cline { 2 - 5 } & Change & $1.98 \pm 1.05$ & $1.68 \pm 1.36$ & 0.546 \\
\hline
\end{tabular}

BM: body mass, BMI: body mass index, Pre: before training measure, Post: after training measure, Change: post-test minus pre-test, SD: standard deviation, P-Values: Chance of significance, ${ }^{*}$ : significant.

In table 1 , the independent t-test showed no alterations between the two training groups of all physical characteristics $(\mathrm{P}>0.05)$. While, the Paired t-tests displayed that the TG-1 revealed increases in BM, BMI, and FFM by $4.6 \%, 4.4 \%$, and $4.6 \%$, respectively ( $\mathrm{P} \leq 0.05)$. The TG-2 also revealed increases in BM, BMI, and FFM by 4.6 , 5.5 , and $3.4 \%$, respectively $(\mathrm{P} \leq 0.05)$.

Table 2. Speed, power, muscular endurance, flexibility, and agility factors recorded at pre- and post-tests.

\begin{tabular}{|c|c|c|c|c|c|c|}
\hline Parameters & Tests & TG-1 (FFM (40-45 kg) & $\mathrm{n}$ & TG-2FFM (46-55 kg) & $\mathrm{n}$ & P-Values \\
\hline \multirow{3}{*}{$\begin{array}{c}20 \mathrm{~m} \text { Run } \\
(\mathrm{Sec})\end{array}$} & Pre & $3.46 \pm 0.19$ & 12 & $3.36 \pm 0.15$ & 14 & 0.188 \\
\cline { 2 - 7 } & Post & $3.21 \pm 0.27$ & 12 & $3.14 \pm 0.23$ & 14 & 0.497 \\
\cline { 2 - 7 } & Change & $-0.24 \pm 0.28$ & 12 & $-0.22 \pm 0.18$ & 14 & 0.790 \\
\hline & Pre & $6.28 \pm 0.47$ & 10 & $6.13 \pm 0.44$ & 14 & 0.452 \\
\hline
\end{tabular}




\begin{tabular}{|c|c|c|c|c|c|c|}
\hline \multirow{2}{*}{$\begin{array}{c}\text { 40m Run } \\
(\mathrm{Sec})\end{array}$} & Post & $6.05 \pm 0.25$ & 10 & $5.83 \pm 0.39$ & 14 & 0.125 \\
\hline & Change & $-0.18 \pm 0.26$ & & $-0.30 \pm 0.22$ & & 0.227 \\
\hline \multirow{3}{*}{$\begin{array}{c}\text { 60m Run } \\
(\mathrm{Sec})\end{array}$} & Pre & $8.89 \pm 0.60$ & 12 & $8.42 \pm 0.48$ & 14 & $0.036^{*}$ \\
\hline & Post & $8.70 \pm 0.65$ & 12 & $8.08 \pm 0.52$ & 14 & $0.013^{*}$ \\
\hline & Change & $-0.18 \pm 0.30$ & & $-0.33 \pm 0.24$ & & 0.199 \\
\hline \multirow{3}{*}{$\begin{array}{l}\text { SLJ } \\
(\mathrm{cm})\end{array}$} & Pre & $184.83 \pm 26.99$ & 12 & $185.43 \pm 27.65$ & 14 & 0.956 \\
\hline & Post & $191.25 \pm 24.01$ & 12 & $192.57 \pm 26.72$ & 14 & 0.896 \\
\hline & Change & $6.42 \pm 5.43$ & & $7.14 \pm 3.59$ & & 0.687 \\
\hline \multirow{3}{*}{$\begin{array}{c}\text { Sit-ups } \\
\text { (reps /30 } \\
\text { Sec) }\end{array}$} & Pre & $17.75 \pm 3.54$ & 12 & $19.79 \pm 4.67$ & 14 & 0.229 \\
\hline & Post & $22.67 \pm 3.82$ & 12 & $23.29 \pm 5.03$ & 14 & 0.731 \\
\hline & Change & $4.92 \pm 2.06$ & & $3.50 \pm 1.87$ & & 0.079 \\
\hline \multirow{3}{*}{$\begin{array}{c}\text { Sit \& Reach } \\
(\mathrm{cm})\end{array}$} & Pre & $25.42 \pm 7.79$ & 12 & $23.93 \pm 9.31$ & 14 & 0.666 \\
\hline & Post & $28.58 \pm 7.93$ & 12 & $26.29 \pm 9.65$ & 14 & 0.518 \\
\hline & Change & $3.17 \pm 2.32$ & & $2.36 \pm 1.59$ & & 0.306 \\
\hline \multirow{3}{*}{$\begin{array}{l}\text { Agility } \\
\text { (Sec) }\end{array}$} & Pre & $18.18 \pm 0.76$ & 12 & $17.95 \pm 0.87$ & 14 & 0.489 \\
\hline & Post & $17.54 \pm 0.74$ & 12 & $17.20 \pm 0.71$ & 14 & 0.243 \\
\hline & Change & $-0.63 \pm 0.44$ & & $-0.75 \pm 0.36$ & & 0.470 \\
\hline
\end{tabular}

n: number of subjects in each group, m: meter, Sec: seconds

The TG-1 increased in SLJ, sit-ups, and sit \& reach by $3.8,29.4$, and $12 \%$, respectively, $\mathrm{P} \leq$ 0.05 ) and decreased in $20 \mathrm{~m}, 40 \mathrm{~m}$, and agility by $7.2,3.6$, and $3.5 \%$, respectively, $\mathrm{P} \leq 0.05$. The TG-2 also elevated by 3.7, 21, and 13\% in SLJ, sit-ups, and sit \& reach, respectively, $\mathrm{P} \leq 0.05$ and decreased by $6.5,4.8,4$, and $4.1 \%$ in $20 \mathrm{~m}$, $40 \mathrm{~m}, 60 \mathrm{~m}$, and agility, respectively, $\mathrm{P} \leq 0.05$. Once, the post-tests were linked with the pretests by the independent $\mathrm{t}$-tests, there were no fluctuations in SLJ, 20m, 40m, 60m run, agility, sit-ups and sit \& reach $(\mathrm{P}>0.05)$. These results can be observed in Table 2 .

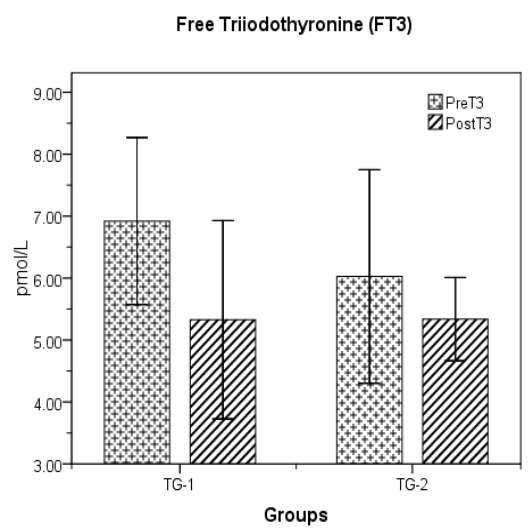

Figure 1: Free Triiodothyronine (FT3) of two training groups measured at pre- and posttraining.

It can be - noticed from Figure 1 that the TG-1 decreased by $23.1 \%$ (from $6.92 \pm 0.67$ to $5.32 \pm$
$0.80 \mathrm{pmol} / \mathrm{l}, \mathrm{P}=0.004)$ - when the post test was compared with the pre-test for individual group separately. The TG-2 also reduced by $11.4 \%$ (from $6.02 \pm 0.86$ to $5.33 \pm 0.33 \mathrm{pmol} / \mathrm{l}, \mathrm{P}=$ $0.026)$. The TG-1 showed greater reduction than the TG-2 $(-1.59 \pm 0.59$ vs $-0.68 \pm 0.62 \mathrm{pmol} / \mathrm{l}$, respectively, $\mathrm{P}=0.30$ ) as soon as the post-tests were subtracted from the pre-tests.

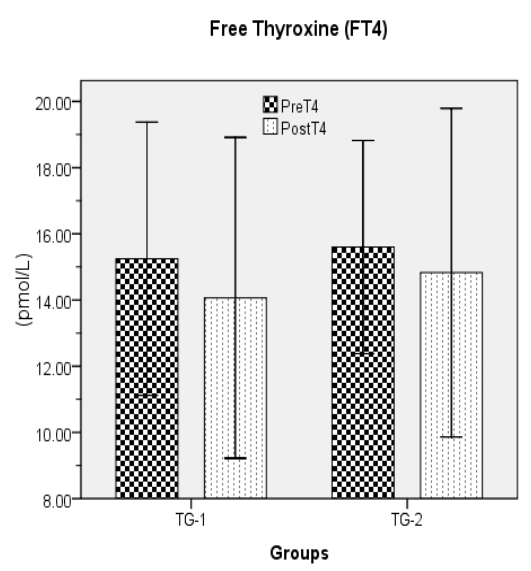

Figure 2: Free Thyroxine (FT4) calculated at pre- and post-exercise

No differences were noted among groups at pretests, post-tests, or post-tests minus pre-tests or within the group; the post-test was compared with the pre-tests independently $(\mathrm{P}>0.05)$ as seen in Figure 2. 


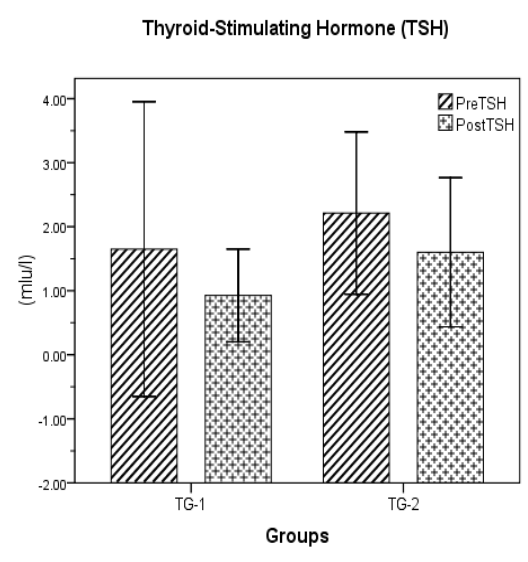

Figure 3. Thyroid-Stimulating Hormone (TSH) measured at pre- and post-training.

Similar outcomes were stated between groups (independent t-test) and within groups (paired t-tests) $(\mathrm{P}>0.05)$. These consequences can be observed in Figure 3.

\section{DISCUSSION}

It was anticipated that the TG-2 (FFM $=46-55$ $\mathrm{kg}$ ) will have noteworthy differences with TG-1 ( $F F M=40-45 \mathrm{~kg}$ ) in entire study components. But it took place since the two groups were amateur and enhanced their performance by parallel proportions after the protocol of training in spite of the substantial variances in the FFM at the start of the training.

The results of this research work showed an affirmative functional impact in FT3 between and within group. These upshots are similar to the earlier outcomes of the research by Simsch et al. (2002) who specified a momentous reduction in FT3 after weight training workouts [28]. Similarity, the conclusions of the current study are in variance with the erstwhile investigation of Alen et al. (1993) who noted a noteworthy rise in FT3 within 7 days of extreme weight training of teenaged female weightlifters [30]. But, Rahimi et al. (2013) and Pakarinen et al. (1988) specified no disparities in FT3 after weight raining [32, 33]. The variations between the present and previous studies may be because of the use of different categories of participants, gender, training standing, and blood sample testing duration. No positive response in the FT4 was detected in the existing study. Likely, our finding corresponding with Simsch et al (2002) and Rahimi et al. 2013, [28, 32]. While
Pakarinen et al. (1988) specified a substantial decline in FT4 [30]. A nonsignificant decrease was noted in TSH in the present study. The consequence was not in line with the previous studies of Simsch et al (2002), Alen et al (1993) and Pakarinen et al (1991) who established worthwhile drip in TSH after resistance training [28, 30, 33]. Rahimi et al. (2013) examined the impact of weight training protocol on thyroid hormones amid men college participants and discovered no variations in TSH after exercise [32]. The influence of 1.5 month of diverse football plyometric with sprint drill on the thyroid and the hypothalamus hormones is debatable as this issue did not take enough attention from researchers and scientists. People with slim personality are an example of ignorance in this area of study.

In the present research work, training influence was witnessed in the $20 \mathrm{~m}$ sprint by $7.2 \%$ (TG-1) and $6.5 \%$ (TG-2), which are similar to the result of Markovic, (2007) of a $3.1 \%$ decrease [16]. Nevertheless, one investigation was not in conformity with this outcome, which reported that exercise groups had identical sprint time recordings ensuing the work out [35]. They linked the influence of two kinds of plyometric workouts on power and agility in young soccer players. The conflict between the study by Thomas and our study may be because of the employment of varied types of participants (trained soccer players by Thomas) [35]. A 20m sprint signifies the acceleration phase; at this juncture, the hip and the knee extensors were the key body segments utilized by the participants to speed up [36, 37]. The underweight subjects performed 12 periods of plyometric exercises (single leg hop, double leg hops, and long jumps) and utilized small sprint spells like $20 \mathrm{~m}$ and $30 \mathrm{~m}$. The above protocol strengthens the hip and knee extensors and participated in the exercise outcomes of the developmental performance among the lean students. It may be attributed due to the decrease in ground interface time from $<200$ milliseconds at speeds up phase to $<100$ milliseconds at extreme stage [38]. In a $40 \mathrm{~m}$ sprint, $3.6 \%$ (TG-1) and $4.8 \%$ (TG-2) reductions were noted. These results are in line with the discovery of Ronnestad, 2008 (1.1\%) and Ratamess, 2007 (5.6\%) [7, 11]. These observations can be endorsed to the fact that the hip and the knee extensors come closer 
explosively to quicken speed; and are considered as the key physical parts in aiding the acceleration stage. The acceleration stage is reliant on reaction time and the athlete's capability to produce force and power of momentum [37]. The hip and the ankle extensors are the greatest participated portion of the body in the maximum speed level [37, 39], which may increase power by sprinting and plyometric exercise. The suppleness of the plantar flexor muscles has a pronounced influence on the accomplishment of the extreme speed of a $40 \mathrm{~m}$ run [11]. The hip flexors [40] and knee extensors [36, 41] are the main contributors in the deceleration phase.

At agility times, 3.5\% (TG-1) and 4.1\% (TG-2) decreases were observed in the present investigation. These values are in agreement with Markovic, 2007 (4.3\%), Kumar, 2013 (1.5\%), Vaczi, 2013 (1.7\%) and Millar, 2006 $(3 \%)[16,19-21]$. In comparison to the above, no changes were found in the agility times [22, 23]. Agility is the capability of the body to alter the direction and is established on the acceleration and deceleration stages of speed [38]. The augmentation in agility can be accredited to improved motor enrollment or neural variation [21], muscle hypertrophy [42], and knee extensor strength [22,36].

In the present investigation, surges of $3.8 \%$ and $3.7 \%$ in SLJ were witnessed in the TG-1 and the TG-2, respectively. These results are in line with observations of Panakal, 2012 (10-14\%), Sadeghi, 2013 (10\%), Ratamess, 2007 (7-9\%), Markovic, 2007 (2.8-3.2\%), and Faigenbaum, 2007 (5.5\%) [8, 10, 11, 20, 24]. Ratamess et al. (2007) indicated that greater contributions of the plantar flexor muscles of the hip, knee, and ankle were $46 \%, 4 \%$, and $50 \%$, respectively during the propulsive phase of the SLJ. Power production [43] was boosted by coordination [44] and neuromuscular adaptations [45] that were produced by the plyometric protocol.

Our conclusion of sit and reach increased by $12 \%$ (TG-1) and 13\% (TG-2). The results are in contradiction of the findings of Sadeghi et al. (2013) who stated no variations after 1.5 month of plyometric workout amongst male swimmers aged 11-14 years [10]. This disagreement may be because of the types (trained athletes) and the age (11-14 years) of the participants. The enhancements in sit and reach can be due to the fact that the intervention regime in the present study was a combined training program. The hamstring and the back muscles are the main contributors in the flexibility test.

Surges of $29.4 \%$ and $21 \%$ in sit-ups were noted in this investigation. These values are in line with the observations of Jafari et al. (2015) who reported an increase of $66.6 \%$ after 8 weeks of circuit strength endurance protocol amongst underweight male college students [25]. The paramount outcome of Jafari can be recognized due to the selection of taller $(177 \mathrm{~cm})$ heftier (59 kg) individuals, and protracted period (8 weeks) and superior frequency (3 days per week) of the training program [25].

\section{CONCLUSION}

It was concluded that 6 weeks of mixed football plyometric with sprint protocol has a training influence on power, muscular endurance, flexibility, speed, and FT3 of 2 groups of lean college male students. It also showed that the two exercise groups had analogous attainment in maximum variables of this research study with regard to the FFM.

\section{REFERENCES}

1. Afifi K, Balbaa AE, Saweeres ES. Can lumbar proprioception Predict Hamstring Strain in Soccer Players? J. Adv. Pharm. Educ. Res. 2019;9(1):82-7.

2. Ibrahim S, Azhar SA. Performance-Related Fitness Variables, and Metabolic and Physiological Components among Athletes, Int. j. pharm. res. Allied sci. 2020; 9(2):8590.

3. Bangsbo J, Norregaard l, Thorso F. Activity profile of competition soccer Canadian Journal of Sport Sciences, 1991; 16(2): 1106.

4. Stølen T, Chamari K, Castagna C, Wisløff U. Physiology of soccer. Sports medicine. 2005 Jun 1;35(6):501-36.

5. de.Villarreal ESS, Requena B, Izquierdo $M$, Gonzalez-Badillo JJ. Enhancing sprint and strength performance: combined versus maximal power, traditional heavyresistance and plyometric training. Journal of Science and Medicine in Sport, 2013;16(2): 146-50. 
6. Herrero AJ, Martin J, Martin T, Abadla O, Fernandez B, Garcia-Lopez D. The shortterm effect of plyometrics and strength training with and without superimposed electrical stimulation on muscle strength and anaerobic performance: a randomized controlled trial. Journal of Strength and Conditioning Research, 2010;24(6):161622.

7. Ronnestad B R, Kvamme N H, Sunde A, Raastad T. Short-term effects of strength and plyometric training on sprint and jump performance in professional soccer players. Journal of Strength and Conditioning Research, 2008;22(3):773-80.

8. Panackal MB, Daniel T, Abraham G. Effects of different training methods on power output among school team players. International Journal of Advanced Scientific and Technical research, 2012; 5(2):56-63.

9. Vijayalakshmi V, Jayabal $T$. Effects of combination of own body resistance exercise and plyometric with and without yogic practices on selected physical and physiological variables among adolescent boys. IJALS, 2013;6(3):246-51.

10. Sadeghi H, Nabavi Nik H, Darchini MA, Mohammadi R. The effect of six-week plyometric and core stability exercises on performance of male athlete. Advances in Environmental Biology, 2013;7(6):11951201.

11. Ratamess N A, Kraemer W J, Volek J S, Ffrench D N, Rubin M R, Gomez A L, Newton R U, Maresh C M. The effects of ten weeks of resistance and combined plyometric-sprint training with the meridian elite athletic shoe on muscular performance in women. Journal of Strength and Conditioning research, 2007;21(3):882-6.

12. Marques, M.C., Pereira, A., Reis, I.G., Tillaar, R.V.D. Does an in-season 6-week combined sprint and jump-training program improve strength-speed abilities and kicking performance in young soccer players? Journal of Human Kinetics, 2013;39(1):15766.

13. Rahimi, R., Behpur, N. The effects of plyometric, weight and plyometric - weight training on anaerobic power and muscular strength. Physical Education and Sport, 2005;3(1):81-91.
14. Rahimi, R., Arshadi, P., Behpur, N., Boroujerdi, S. S., Rahimi, M. Evaluation of plyometrics, weight training and their combination on angular velocity. Physical Education and Sport, 2006;4(1):1-8.

15. Ross, R. E., Ratamess, N. A., Hoffman, J. R., Faigenbaum, A. D., Kang, J., Chilakos, A. The effects of treadmill sprint training and resistance training on maximal running velocity and power. Journal of Strength \& Conditioning Research, 2009;23(2):385-94.

16. Markovic, G., Jukic, I., Milanovic, D., Metikos, D. Effects of sprint and plyometric training on muscle function and athletic performance. Journal of Strength and Conditioning Research, 2007;21(2):543-9.

17. Hagag OM, Al-Balah OF, Balbaa AA, El-Azizi $\mathrm{HM}$, Eid GS. $905 \mathrm{~nm}$ Laser Diode and Platelet-rich plasma in the Treatment of the Second-degree Hamstring tear. J. Adv. Pharm. Educ. Res. 2020;10(4):43-7.

18. Robert, A., Murugavel, K. Effect of plyometric resistance and sprint training on acceleration speed flight time and jump height of male basketball players. International Journal of Life Sciences and Educational Research, 2013;1(3):105-9.

19. Kumar, R. The effect of 6-week plyometric training program on agility of collegiate soccer players. International Journal of Behavioural, Social and Movement Sciences, 2013;102(1):170-6.

20. Vaczi, M., Tollar, J., Meszler, B., Juhasz, I., Karsai I. Short-term high intensity plyometric training program improves strength, power and agility in male soccer players. Journal of Human Kinetics, 2013;36(1):17-26.

21. Miller, M. G., Herniman, J. J., Ricard, M. D., Cheatham, C. C., Michael, T. J. The effects of a 6-week plyometric training program on agility. Journal of Sports Science and Medicine, 2006;5(3):459-65.

22. Lehnert, M., Hulka, K., Maly, T., Fohler, J., Zahalka, F. The effects of a 6-week plyometric training program on explosive strength and agility in professional basketball players. Acta Univ. Palacki. Olomuc. Gymn, 2013;43(4):7-15.

23. Zghal, F., Chortane, G., Gueldich, H., Mrabet, I., Messoud, S., Tabka, Z., Cheour, F. Effects of in-season combined training on running, 
jumping, agility and rate of force development in pubertal soccer players. IOSR-JPBS, 2014;9(4):21-2

24. Faigenbaum, A. D., McFarland, J. E., Keiper, F. B., Tevlin, W., Ratamess, N. A., Kang, J., Hoffman, J. R. Effects of a short-term plyometric and resistance training program on fitness performance in boys age 12 to 15 years. Journal of Sports Science and Medicine, 2007;6(4):519-25.

25. Jafari, S., Rahnani-nia, F., Arazi, H. The effect of a circuit strength-training program on the muscle strength, body image and anxiety of anxious underweight male college students. Hrvat. Sportskomed. Vjesn, 2015;30(1):429.

26. Katherine, M. F., Brian, K. Kit., Barry, I. G. Body Mass Index Categories in Observational Studies of Weight and Risk of Death. American Journal of Epidemiology, 2014; 180 (3): 288-96.

27. Mahassni SH. Overweight and Obesity and the Immune System, Lipids and $\mathrm{C}$ - reactive protein in Young and Middle-aged Saudi Female University Workers. J. Biochem. Tech. 2020;11(1):49-56.

28. Simsch, C., Lormes, W., Petersen, K.G., Baur, S., Liu, Y., Hackney, A.C., Lehmann, M., Steinacker, J.M. Training intensity influences leptin and thyroid hormones in highly trained rowers. Int. J Sports Med, 2002;23(06):422-7.

29. Ibrahim, S., Al-Ameer, A., Abu-Hilal, H., Allen, J., Watkins, P. Effect of Protein Supplementation plus Hyper-Caloric intake and Exercise on Hypertrophy, Hormones and Energy components among Underweight Males, International Journal of Pharmaceutical Research \& Allied Sciences, 2020;9(3):143-53.

30. Alen, M., Pakarinen, A., Hakkinen, K. Effects of prolonged training on serum thyrotropin and thyroid hormones in elite strength athletes. J. Sport. Sci, 1993;11(6):493-7.

31. Peeri, M., Boostani, M.H., Banaeifar, A., Kohanpour, M.A., Erfani, M., Abbariki, Z. Effect of eight weeks continuous resisting training on relaxation levels and responses of active young women' thyroid hormones to one turn sport. J. Basic. Appl. Sci. Res, 2013;3: 648-53.
32. Rahimi, E., Zadeh, Y.M., Boostani, M.A. The effect of resistance training on thyroid hormones. European Journal of experimental Biology, 2013;3(2):443-7.

33. Pakarinen A, Alén M, Häkkinen K, Komi P. Serum thyroid hormones, thyrotropin and thyroxine binding globulin during prolonged strength training. Eur. J. Appl. Physiol, 1988;57(4):394-8.

34. Siri, W. E. Body composition from fluid spaces and density: Analysis of methods. A technique for measuring body composition. J. Brozek and A. Henschel, eds. Washington, DC: National Academy of Science, 1961.

35. Thomas, K., French, D., Philip, R. The effect of two plyometric training techniques on muscular power and agility in youth soccer players. Journal of Strength \& Conditioning Research, 2009;23(1):332-5.

36. Delecluse, C. Influence of strength training on sprint running performance. Current findings and implications for training. Sports Med, 1997;24(3):147-56.

37. Mero, A., Komi, P.V., Gregor, R.J. Biomechanics of sprint running: a review. Sports Med, 1992;13(6):376-92.

38. Plisk, S.S. Speed, agility, and speedendurance development, in: T.R. Baechle and R.W. Earle (Eds), Essentials of Strength Training and Conditioning, Champain: Human Kinetics Books, 2000; 471-92.

39. Wiemann, K., Tidow, G. Relative activity of hip and knee extensors in sprintingimplications for training. New Studies in Athletics, 1995;10: 29-49.

40. Mann, R.A., Moran, G.T., Dougherty, S.E. Comparative electromyography of the lower extremity in jogging, running, and sprinting. Am. J. Sports Med, 1986;14(6): 501-10.

41. Dowson, M.N., Nevill, M.E., Lakomy, H.K.A., Nevill, A.M., Hazeldine, R.J. Modelling the relationship between isokinetic muscle strength and sprint running performance. J. Sports Sci, 1998;116(3):257-65.

42. Malisoux, L., Francaux, M., Nielens, H., Theisen, D. Stretch-shortening cycle exercises: an effective training paradigm to enhance power output of human single muscle fibers. J Appl Physiol, 2006;100(3): 771-9.

43. Chelly, M. S., Ghenem, M. A., Abid, K., Hermassi, S., Tabka, Z., Shephard, R. J. 
Effects of in-season short-term plyometric training program on leg power, jump-and sprint performance of soccer players. Journal of Strength and Conditioning Research, 2010; 24(10): 2670-6.

44. de.Villarreal, E.S., Kellis, E., Kraemer, W.J, Izquierdo, M. Determining variables of plyometric training for improving vertical jump height performance: A meta-analysis. J
Strength Cond Res, 2009; 23(2): 495-506.

45. Kraemer, W. J., Ratamess, N. A., Volek, J., Mazzetti, S. A., Gomez, A. L. The effect of the meridian shoe on vertical jump and sprint performances following short-term combined plyometric/sprint and resistance training. Journal of Strength \& Conditioning Research, 2000; 14(2): 228-38. 